Journal of Engineering and Applied Sciences 14 (Special Issue 8): 10437-10441, 2019

ISSN: $1816-949 \mathrm{X}$

(C) Medwell Journals, 2019

\title{
Influence of the Dope on a Semi-Granular Bitumen Mixture Silexite
}

\author{
${ }^{1}$ Souleymane Mbengue, ${ }^{2}$ Djibril Sow, ${ }^{2}$ Astou Diokhané, ${ }^{3}$ Fatou Samb, ${ }^{3}$ Makhali Ba and \\ ${ }^{4}$ Ibrahima Khalil Cisse \\ ${ }^{1}$ Henan China Company Based in Senegal \\ ${ }^{2}$ Institut Universitaire de Technologie, Université de Thiès, \\ Ministère de 1'Enseignement Supérieur de la Recherche et de 1'Innovation, Thiès, Sènègal \\ ${ }^{3}$ Unité de Formation et de Recherches en Science de 1'Ingénieur, Université de Thiès, Ministère de \\ 1'Enseignement Supérieur de la Recherche et de 1'Innovation, Thiès, Sènègal \\ ${ }^{4}$ Ecole Polytechnique de Thiès, Ministère de l'enseignement Supérieur de la \\ recherche et de l'innovation, Thiès, Sènègal
}

\begin{abstract}
The purpose of this research is to study the impact of the dope product on a semi-granular bituminous silexite mixture. The new tested material which is silexite is recognized as a sedimentary rock derived from industrial waste from phosphate mining by the chemical industries of Senegal. It has captured the attention of researchers by its quantity, proximity and hardness to make it undergo mechanical and physical tests and to associate it with the hydraulic binder and dope products, so that, it can be an alternative solution to the basaltic material which is becoming rarer and boring day by day. In a first one a mechanical characterization of the material is operated through the tests Los Angeles and Micro Deval which gives satisfactory results for a use of the material in wearing course. Then, it is mixed alone with a $35 / 50$ hydrocarbon binder to form a semi-grained bituminous concrete. The performances obtained do not give enough satisfaction if one refers to the ratio immersion compression which is equal to $0.67<0.70$. This report provides information on the ability of the material to resist stripping in the presence of water. So, a lack of adhesiveness has arisen between the binder and the granulate. Following this, it is added two types of dopes namely CECABASE and ITERLENE. Improvements in performance from the point of view of stability, creep and compaction are noted. It has also been found that CECABASE gives better results than ITERLENE. At the end of the analysis made on the silexite material, it is retained that the addition of adhesive dope positively influences on different scales depending on the type, the performance of the bituminous mixture in the presence of water.
\end{abstract}

Key words: Dope, silexite, semi-grouted bituminous concrete, binder, adhesiveness, water, CECABASE, ITERLENE

\section{INTRODUCTION}

Silexite is a sedimentary rock found in Senegal in abundant quantities. Recent quantitative studies have yielded an estimated volume of $22,688,822 \mathrm{~m}^{3}$. Silexite is an ambiguous term for both cherts forming part of the calcareous rock that contains them (Cayeux, 1929) and igneous rocks consisting essentially of quartz (Lexicon, 1919) ("lexique" s.d).

It comes from industrial waste from phosphate mining by the chemical industries of Senegal. Its use in road construction in Senegal is not yet experienced. The material commonly used is the basalt which becomes scarce and becomes more expensive. Currently in Senegal, almost only Diach's basaltic quarry is in operation and does not cover all needs. This study will firstly test the mechanical and physical performance of the silexite material to understand its intrinsic characteristics and fabrication. Then, it will be combined with a hydrocarbon binder and then with dope products to determine its mechanical behavior in terms of stability, creep, compactness and water resistance.

The adhesion of bituminous binders to aggregates is a factor that has a major influence on the life of an asphalt concrete. Doping can also influence the stickiness parameters (Rychen et al., 2010).

Dope is a chemical that helps promote adhesiveness between two materials. In the case of bituminous mixes, the adhesive dopes already allow small amounts to improve the affinity of the aggregates, especially when they are humid, relative to the hydrocarbon binder. The dopes are for the most part surfactants that modify the coating of the aggregates with the binder and improve the bonds between them. The use of adhesiveness dope allows a significant improvement in the adhesiveness, mainly when the binder/aggregate pair is little or not compatible, for example in the case of siliceous granules. As part of this study, we will use CECABASE and 
ITERLENE which are two different dope products and see their influence on the bitumen mixture through the Marshall and Duriez test.

Cecabase ${ }^{\circledR}$ RT is a relatively new additive in WMA technology and only a few laboratory experiments have been performed (Goh et al., 2013).

To achieve a desired level of adherence to a pavement and the maintenance of this performance over time, it is possible to act on the road formulas and the nature of the aggregates (Ledee et al., 2005).

\section{MATERIALS AND METHODS}

Characterization of silexite aggregates: The silexite aggregates used come from Keur Mor Fall slag in Mboro in the Thies region operated by SOCAM. They are taken by poor care and received at the CEREEQ laboratory (Experimental Research and Study Center for Equipment). They have been listed as follows:

- $\quad$ Silexite $8 / 14$

- $\quad$ Silexite $3 / 8$

- Silexite $0 / 3$

Table 1 gives the results obtained on the particle size analysis according to the standard EN 933-1

Particle size analysis: It is found that from the point of view granularity ( $\%$ refusal to $D$ for chippings, $\%$ passing to $\mathrm{d}$ for gravel, $\%$ refusal to $\mathrm{D}$ for sands):

For $8 / 14$

$\%$ rejection at $14=2.7<15 \%$

$\%$ to $8=20.62>15 \%$

For $3 / 8$

$\%$ of refusal at $8=6.5<15 \%$

$\%$ of $3=1<15 \%$

Table 1: Granulometric analysis $\%$ of pass in the sieve

Sieve $10 .-14$

\begin{tabular}{llllll}
\hline 44 & 20 & - & - & -
\end{tabular}

$\begin{array}{lllll}44 & 20 & - & - & - \\ 43 & 16 & - & - & 100\end{array}$

$\begin{array}{lllll}42 & 14 & - & - & 97.3\end{array}$

$\begin{array}{lllll}41 & 12.5 & - & - & 91.92\end{array}$

$\begin{array}{lllll}40 & 10 & - & 100 & 46.28\end{array}$

$\begin{array}{lllll}39 & 8 & - & 93.5 & 20.62\end{array}$

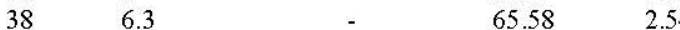

$\begin{array}{lllll}37 & 5 & - & 40.62 & 0.44\end{array}$

$\begin{array}{lllll}35 & 4 & 100 & 15.84 & 0.38\end{array}$

$\begin{array}{lllll}32 & 3.15 & 95.6 & 2.34 & -\end{array}$

$\begin{array}{lllll}29 & 2.5 & 88 & 0.8 & -\end{array}$

26

$23 \quad 1.25$

$20 \quad 0.63$

- $\quad 0.5$

- $\quad 0.315$

0.16

0.08

-

$-$

18
For $0 / 3$

$\%$ of refusal at $3=6<15 \%$

class $8 / 14$ exceeds the limit value ( $\%$ passing to $8=$ $20.62>15 \%$ ).

On the other hand, the other classes respect the specifications of the standard NF EN 933-1 May 2012. This reflects an acceptable crushing of the material except for the class declared $8 / 14$. Hence, the need to pay special attention to crushing in order to be in the eligible areas.

On the basis of the data obtained concerning the particle size analysis, the following curves are established. Figure 1 granulometric curve of the different granular classes. Table 2 gives the results obtained on the characterization of intrinsic parameters and fabrication of the silexite material for its use in asphalt concrete.

In general, the silexite material has acceptable mechanical and physical characteristics for use in semi-grained bituminous concrete. However, the cleanliness needs to be improved as well as the crushing operation to be within tolerances.

Characteristics of bitumen: As part of this study, the following tests are carried out on bitumen:

- $\quad$ Bitumen penetration test (EN 1426)

- $\quad$ Ring and ball softening point (EN 1427)

The penetrability at $25^{\circ} \mathrm{C}$ is 42 and the ball and ring softening temperature is $55^{\circ} \mathrm{C}$ between 50 and 58 . The bitumen analyzed satisfies the characteristics of the $35 / 50$ class and is within the range of the acceptable softening temperatures defined by EN 1427.

\section{Determination of theoretical mixtures and content by binding}

Determination of the granulometric curve of the mixture: From the granulometric curves of the different granular classes of the silexite material, a mixture is selected whose curve is inscribed within the limits of the

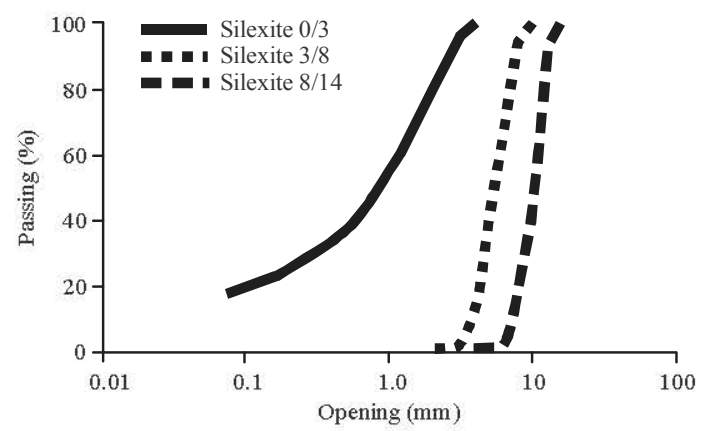

Fig. 1: Granulometric curve of the different granular classes 
Table 2: Physical and mechanical identification of the silexite material for use in asphalt concrete

\begin{tabular}{|c|c|c|c|c|c|}
\hline Measured parameters & $0 / 3$ & $3 / 8$ & $8 / 14$ & Specifications BB 0/14 & Conformity \\
\hline \% refusal of D for chippings & - & 6.5 & 2.7 & $<15 \%$ & Consistent \\
\hline$\%$ of passant to $\mathrm{D}$ for chippings & - & 2.34 & 20.62 & $<15 \%$ & Consistent for all samples except for silexite $8 / 14$ \\
\hline$\%$ of refusal to D for sands (on curves) & 4.4 & - & - & $<15 \%$ & Consistent \\
\hline Specific weight & 2.342 & 2.421 & 2.413 & - & - \\
\hline Equivalent of sand & 4.1 & - & - & $>55 \%$ (a) & Non consistent \\
\hline flattening & - & 15.41 & 17.11 & $<25$ (III) & Consistent \\
\hline Coefficients LA (\%) & - & 23.5 & 22.6 & $\begin{array}{l}\leq 25(\mathrm{~B} \text { for } \mathrm{T}>\mathrm{T} 2) \text { et } \\
\leq 30(\mathrm{C} \text { for } \mathrm{T}<\mathrm{T} 2)\end{array}$ & Consistent \\
\hline $\operatorname{MDE}(\%)$ & - & 10.4 & 12.8 & $\begin{array}{l}\leq 20(\text { B pour } \mathrm{T}>\mathrm{T} 2) \text { et } \\
\leq 25(\mathrm{C} \text { for } \mathrm{T}<\mathrm{T} 2)\end{array}$ & Consistent \\
\hline LAMDE & - & 33.9 & 35.4 & $\begin{array}{l}\leq 35(\mathrm{~B} \text { for } \mathrm{T}>\mathrm{T} 2) \text { et } \\
\leq 45(\mathrm{C} \text { for } \mathrm{T}<\mathrm{T} 2)\end{array}$ & $\begin{array}{l}\text { Slightly non-conpliant for selexite for use in } \mathrm{BB} \\
\text { for traffic }>\mathrm{T} 2\end{array}$ \\
\hline
\end{tabular}

Table 3: Granular composition

\begin{tabular}{ll}
\hline Granular class & Proportion $(\%)$ \\
\hline & Asphaltic concrete $0 / 14$ \\
$0 / 3$ & Silexite \\
$3 / 8$ & 45 \\
$8 / 14$ & 25 \\
\hline
\end{tabular}

Table 4: Binder content according to the wealth module

\begin{tabular}{ll}
\hline Wealth module K & Binder content (\%) \\
\hline 3.3 & 6.1 \\
3.4 & 6.29 \\
3.5 & 6.47 \\
3.6 & 6.65 \\
3.7 & 6.84 \\
\hline
\end{tabular}

Table 5: Marshall test program

Granular composition

Variation in bitumen content TL (\%)

\section{Mixture 1}

$30 \%$ of $8 / 14$

$25 \%$ of $3 / 8$

$45 \%$ of $0 / 3$

Mixture 2

$30 \%$ of $8 / 14$

$25 \%$ of $3 / 8$

$45 \%$ of $0 / 3$

$0.2 \%$ CECABASE

Mixture 3

$30 \%$ of $8 / 14$

$25 \%$ of $3 / 8$

$45 \%$ of $0 / 3$

$0.15 \%$ ITERLENE

spindle defined for a bituminous concrete $0 / 14$. The following granular composition is determined (Fig. 2). By observing the curve we realize that the mixture fits into the spindle (Table 3 ).

\section{Determination of the binder content:}

- The TLext binder content is by definition

- $\quad$ TLext $=100 \times \mathrm{M} \_\mathrm{b} / \mathrm{M} \_\mathrm{GS}$

- With $\mathrm{Mb}=$ Mass of bitumen

- $\mathrm{MGS}=$ Mass of dry aggregates

The theoretical calculations carried out made it possible to obtain the binder contents as a function of module e wealth reported in Table 4.

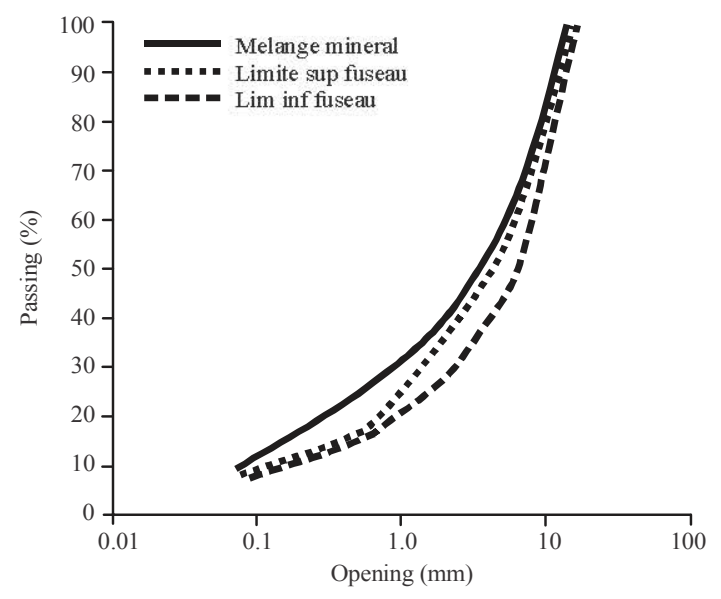

Fig. 2: Granulometric curve of the mixture

Experimental studies: In this section, we will discuss the experimental results obtained from the mineral mixture with the bituminous binder alone. Then the bituminous mixture in combination with two different types of dope namely CECABASE 260 and ITERLENE IN/400. CECABASE is a dope of adhesiveness used at very low dosage and which improves the coating of aggregates, tack bitumen-pebbles and therefore increases the water resistance.

ITERLENE is a very high performance liquid antisttripping which guarantees a perfectly stable bond between bitumen and aggregates in all application conditions, ensures mechanical stability, reduces stability loss. It is highly compatible with bitumen without modifying its physical characteristics (penetration and rheological properties). The equipment used is that of the laboratory of the Experimental Center for Research and Studies for Equipment in Senegal (Table 5).

The results obtained lead us to draw up a Marshall test program with three mixtures of variable binder contents and an addition of two different types of dope in the two mixtures. This is the CECABASE 260 titrated at $0.2 \%$ of the mass of bitumen and ITERLENE IN/400 dosed at $0.15 \%$ of the mass of the bitumen. 
The Marshall tests are carried out according to standardNF EN 12697-34 of August, 2012 (Table 5). The purpose of this test is to determine the mechanical characteristics (stability, creep) as well as the percentage of voids of the compacted bituminous mixture under normal conditions.

Five sets of specimens are made for mixing with binder contents ranging from 6.1-6.84. The evolution curve of the compactness is represented in a graph for each mixture. The grades with which good compacities are obtained will then be selected. The evolution curves of stability and creep are represented in other graphs. A verification of the criterion of preselected contents for these parameters will be made.

The principle of the Duriez test, according to standard NF P 98-25-1 is manufactured by double-acting static compaction, specimens of which some are subjected to the compression test after storage at $18^{\circ} \mathrm{C}$ under conditions defined (in air and in water). Others are intended for the measurement of the density by hydrostatic weighing to calculate the compactness. For the mixture, 07 test pieces were made and distributed as follows:

- The 02 tested in simple compression after $24 \mathrm{~h}$

- The 02 tested in simple compression after 07 days of storage in air at $18^{\circ} \mathrm{C}$

- The 02 tested in simple compression after 07 days of storage in water $18^{\circ} \mathrm{C}$

- One reserved to determine the compactness of the mixture

For each parameter, a figure is presented with the values obtained and the limit values generally retained by the technical prescriptions.

\section{RESULTS AND DISCUSSION}

Results obtained on Marshall trials: Table 6 shows the results obtained on the Marshall test for these results made it possible to draw the following curves (Fig. 3):
Concerning the Marshall stability, all the bitumen contents provide a mechanical resistance higher than the threshold value which is $1000 \mathrm{Kgf}$ except for the mixture with the ITERLENE dope which gives a value of $980 \mathrm{kgf}$ with a binder content of 6.8 .

There is a dominance of the mixture with the CECABASE dope in terms of stability on the other two mixtures However, Marshall stability is not an absolute measure of resistance. In other words, the Marshall test gives no indication of the resistance to deformation of a coating but serves as a control of the regularity of a production of bituminous coating (Fig. 4).

Figure 4 gives an evolution of the compactness as a function of the binder content used. It is found that in terms of compactness with respect to the established limit values, the mixture with CECABASE and ITERLENE fits perfectly in the acceptability range. On the other hand, the mixture without dope has a part of the compactness outside the upper limit (Fig. 5).

By observing the evolution of the fluings, it is noted that all the two mixtures with addition of dope fulfill the conditions set for all levels of binder. On the other hand,

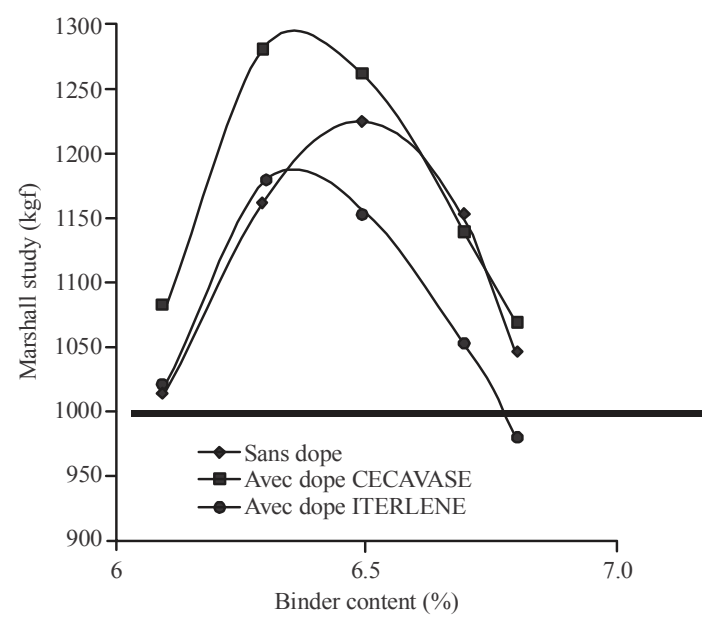

Fig. 3: Evolution of Marshall stability as a function of bitumen content

Table 6: Results of Marshall test

\begin{tabular}{|c|c|c|c|c|c|}
\hline \multirow{2}{*}{$\begin{array}{l}\text { Granular composition } \\
\text { Mixture } 1 \text { without dope }\end{array}$} & \multicolumn{2}{|c|}{\begin{tabular}{l} 
Silexite $(8 / 14: 30 \%)$ \\
\hdashline-1.0
\end{tabular}} & \multirow[t]{2}{*}{$\begin{array}{l}\text { Silexite }(3 / 8: 25 \%) \\
-\cdots--\end{array}$} & \multicolumn{2}{|c|}{ Silexite $(0 / 3: 45 \%)$} \\
\hline & & & & & \\
\hline Binder content $(\%)$ & 6.1 & 6.3 & 6.5 & 6.7 & 6.8 \\
\hline Stability (kgf) & 1013 & 1166 & 1226 & 1153 & 1040 \\
\hline Compactness (\%) & 94.81 & 95.8 & 97.15 & 96.69 & 96.73 \\
\hline Creep (mm) & 3.23 & 3.35 & 3.69 & 4.08 & 4.36 \\
\hline Mixture 2 with the dope & & & & & \\
\hline Stability at $60^{\circ}$ & 1080 & 1280 & 1260 & 1140 & 1067 \\
\hline Compactness $(\%)$ & 95.88 & 96.17 & 96.67 & 96.5 & 96.38 \\
\hline Creep (mm) & 3.27 & 3.53 & 3.59 & 3.63 & 3.73 \\
\hline Mixture 3 with the dope & & & & & \\
\hline Stability at $60^{\circ}$ & 1020 & 1180 & 1153 & 1053 & 980 \\
\hline Compactness $(\%)$ & 95.7 & 96.12 & 96.18 & 96.19 & 96.24 \\
\hline Creep (mm) & 3.14 & 3.35 & 3.45 & 3.64 & 3.71 \\
\hline
\end{tabular}




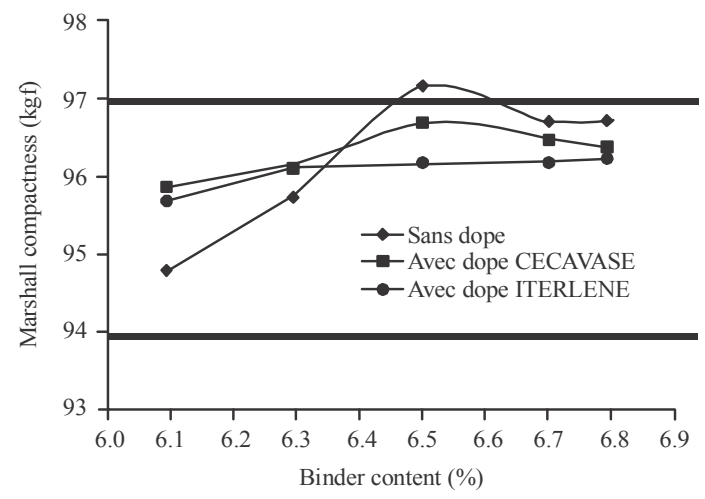

Fig. 4: Evolution of the Marshall compactness according to the binder content and the dope

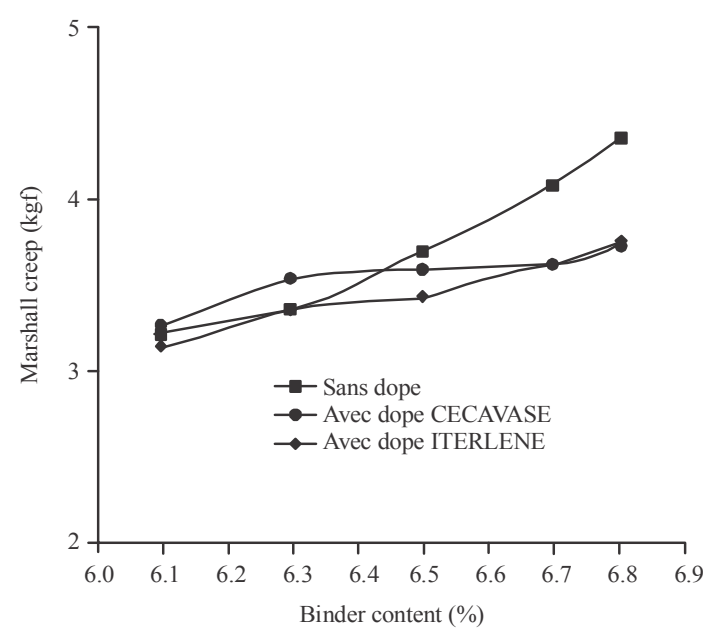

Fig. 5: Evolution of Marshall creep as a function of bitumen content and the dope

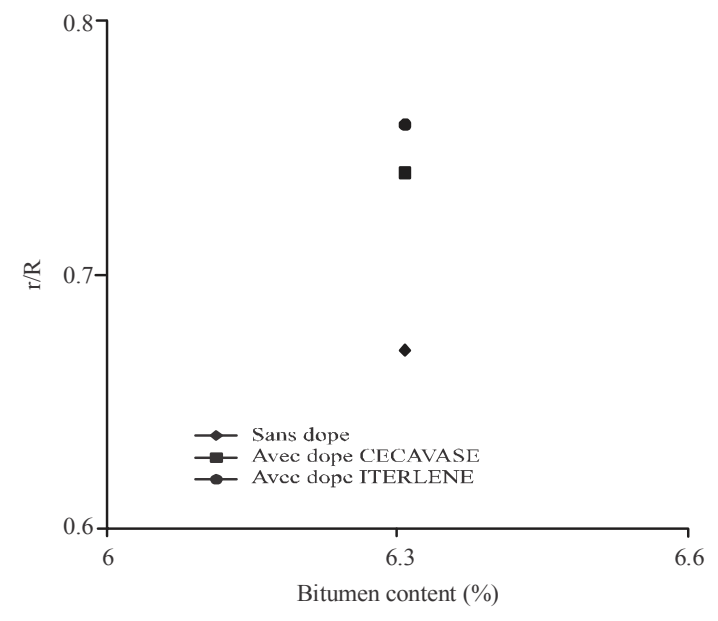

Fig. 6: Evolution the immersion/compressionration to the bitumen content for the mixture without dope, the flows deviate from the allowable threshold from the content of 6.7. Following the analysis of the results obtained on the Marshall test, an evaluation of the water sensitivity (Duriez test) is adopted with the bitumen content of $6.3 \%$ which is the value of the binder content better all the criteria.

Immersion/compression ( $\mathbf{r} / \mathbf{R})$ : The ratio of the compressive strength of specimens stored for 7 days in water at $18^{\circ} \mathrm{C}$ to those stored in air at the same temperature was calculated for each mixture. The results obtained are shown in Fig. 6.

For a binder content of $6.3 \%$, the mixtures with CECABASE and ITERLENE dopes have respective $r / R$ ratios of 0.74 and 0.76 higher than the required minimum value of 0.70. ITERLENE compared to CECABASE on the basis of this study gives a better behavior compared to the sensitivity to the water and the stripping. On the other hand, the mixture without dope provides a result below the threshold value.

\section{CONCLUSION}

At the end of this study, it turns out that dope products give the bitu-megasm mixture the best performances that best fulfill the conditions set by the technical prescriptions.

So, depending on the desired criteria, it will be necessary to make a wise choice on the type of dope to use. In the future, more advanced studies are needed to better predict the mechanical and physical behavior of the silexite material.

\section{REFERENCES}

Cayeux, L., 1929. Ambiguous term designating both the cherts forming a body and the limestone that contains them. Miller Electric, Appleton, Wisconsin, USA.

Goh, S.W., M.R.M. Hasan and Z. You, 2013. Performances evaluation of Cecabase ${ }^{\circledR} \mathrm{RT}$ in warm mix asphalt technology. Procedia Soc. Behav. Sci., 96: 2782-2790.

Ledee, V., G. Delalande and P. Dupont, 2005. Adhesion and aggregates. Bridge Liaison Bull., 255: 91-116.

Lexicon, S.D., 2018. Lexicon of sedimentary geology. University of Liege, Liege, Belgium. http://www. geolsed.ulg.ac.be/sedim/lexique.htm

Rychen, P., M. Pittet and A.G. Dumont, 2010. [Determination of the presence and effectiveness of dope in bituminous concretes]. Zuerich, Office federal des routes (OFROU), Switzerland. (In French) https://infoscience.epfl.ch/record/153410 